\title{
Correlations between Maternal Metabolism and Deranged Development in the Offspring of Normal and Diabetic Rats
}

\author{
JOHAN STYRUD, LENNART THUNBERG, OLOF NYBACKA, AND ULF J. ERIKSSON \\ Department of Medical Cell Biology, University of Uppsala, Biomedicum, S-751 23, Uppsala, Sweden \\ [J.S., U.J.E.]; Department of Clinical Chemistry, University of Agricultural Sciences, S-750 07, \\ Uppsala, Sweden [L.T.]; and Department of Surgery, University Hospital of Uppsala, \\ S-751 85 Uppsala, Sweden [O.N.]
}

In an attempt to define the pathogenesis of congenital malformations in diabetic pregnancy, a number of serum factors were determined in normal and diabetic pregnant rats and correlated to the outcome of gestation with the aid of multivariate linear regression analysis. The animals were from two different lines of Sprague-Dawley rats with documented differences in rates of fetal dysmorphogenesis in diabetic pregnancy. The diabetic rats increased less in body weight than the normal rats, yet displayed increased liver and kidney weights. The serum concentrations of glucose, $\beta$-hydroxybutyrate, triglycerides, the branched-chain amino acids, and asparagine, proline, alanine, citrulline, tyrosine, and ornithine were increased by diabetes. In contrast, IGF-I, glutamic acid, glutamine, cystine, and lysine were decreased in the serum of the diabetic pregnant rats. The maternal metabolic imbalance exerted profound effects on embryonic development. Thus, the embryos of the diabetic rats were smaller, had fewer somites, and contained less DNA and protein than the control embryos. In addition, the resorption and malformation rates were increased in the embryos of the diabetic rats. The regression analysis of the data revealed significant interrelationships between adverse embryonic outcome (rates of malformations and resorptions) and the maternal serum concentrations of glucose, triglycerides, $\beta$-hydroxybutyrate, branched- chain amino acids, and creatinine. This suggests that the maternal metabolism of the three major classes of nutrients covariates with the embryonic development in diabetic rat pregnancy. The monitoring of only one of these maternal parameters, e.g. the serum glucose concentration, may therefore not adequately predict the developmental status of the offspring. Our results suggest that the pathogenesis of fetal malformations in diabetic pregnancy is multifactorial. Thus, maintaining metabolites from all nutrient classes at a normal level may be important in preventing adverse fetal outcome. (Pediatr Res 37: 343-353, 1995)
ALP, alkaline phosphatase

\section{Abbreviations}
HD rats and HD embryos, manifestly diabetic rats and their offspring of the $\mathrm{H}$ strain
HN rats and HN embryos, normal rats and their offspring of the $\mathrm{H}$ strain
UD rats and UD embryos, manifestly diabetic rats and their offspring of the $U$ strain
UN rats and UN embryos, normal rats and their offspring of the $U$ strain
ANOVA, analysis of variance

Diabetic pregnancy is associated with an increased risk of fetal maldevelopment (1-3). The pathogenesis of congenital malformations in the offspring of diabetic mothers is unknown. In previous clinical and experimental studies, strict metabolic control of the mother has been shown to diminish the risk of fetal maldevelopment, especially if the improved control is initiated in early pregnancy (4-7) or before conception (8).

Received October 21, 1993; accepted October 4, 1994.

Correspondence: Johan Styrud, M.D., Department of Medical Cell Biology, University of Uppsala, Biomedicum, P.O. Box 571, S-751 23 Uppsala, Sweden.

Supported by The Swedish Diabetes Association, The Bank of Sweden Tercentenary Foundation, The Juvenile Diabetes Foundation International, The Novo Nordisk Foundation, The Ernfors Family Fund, and The Swedish Medical Research Council (Grant 12X-7475).
Maintenance of normal serum glucose levels alone, however, does not seem to completely protect the fetus from malformations (9). Other disturbed metabolic processes in the mother, reflected by alterations in serum levels of associated metabolites, may therefore have pathogenic roles in the teratogenicity of diabetic pregnancy.

In previous studies of an animal model for diabetic pregnancy, we found increased rates of fetal malformations and resorptions among the offspring of streptozotocin-diabetic rats of a Sprague-Dawley strain, hereafter denoted as $U$ rats $(6,10)$. The course and outcome of gestation in rats from a related strain ( $\mathrm{H}$ rats) $(10,11)$ with no malformations in diabetic pregnancy have been compared with those of the $U$ rats in an attempt to characterize the genetic factors that predispose to 
skeletal malformations in the $U$ strain. The results indicated that this predisposition is related to both the maternal and fetal genome, i.e. the involvement of at least one gene on the maternal and fetal side (11). In another study, however, there were only marginal differences in carbohydrate and lipid metabolites in the $\mathrm{U}$ and $\mathrm{H}$ rat mothers despite a grossly increased malformation rate in the $\mathrm{U}$ offspring compared with the rate in the $\mathrm{H}$ fetuses (12). That study was undertaken at the end of gestation, which may have diminished the possibility of finding teratologically pertinent maternal changes, because the malformations are induced during the first half of pregnancy $(5$, 13-15). Screening of maternal metabolites should therefore take place earlier in pregnancy to find correlations of teratologic importance, a consideration that forms one of the theoretical prerequisites of our study. A period of special interest in this context is gestational $\mathrm{d} 6-10$ in the $\mathrm{U}$ rat, a time interval when uncompensated maternal diabetes has been shown to induce skeletal malformations in the fetuses (14).

In addition to malformations, the offspring of diabetic rats also display growth retardation at birth $(5,6,16-19)$, as well as during the embryonic period (20). Our study therefore also aimed to search for maternal parameters correlating with the embryonic-fetal growth retardation in diabetic pregnancy, parameters not necessary identical to those associated with embryonic malformations.

The aim of our study was to evaluate the embryonic development (implantations, resorptions, general morphologic development, and occurrence of malformations) during the early organogenesis in normal and manifestly diabetic rats of the $U$ and $\mathrm{H}$ strains and to statistically relate the outcome of the pregnancy with the metabolic state of the mother. For this purpose, a series of metabolites and one specific-growth factor (IGF-I), all of which were expected to be altered by diabetes, were determined in the serum of the pregnant rats. These serum factors were chosen to yield an assessment of the maternal state with respect to the three major classes of nutrients (carbohydrates, lipids, and proteins), as well as to the functional status of the kidneys, liver, and heart. A possible coupling between lowered growth-stimulating influences, growth retardation, and malformations in the offspring was investigated by including IGF-I in the analysis. This growth factor is decreased in serum of pregnant diabetic women with suboptimal metabolic control (21), i.e. in pregnancies with increased risk for fetal maldevelopment (4).

The embryonic parameters describing the outcome of pregnancy were morphologic (number of implantations, resorptions and malformations, malformation score, crown-rump length, and somite number) and biochemical (DNA and protein content) in nature. They were chosen to mirror, as thoroughly as possible, the alterations of the embryonic development caused by the maternal diabetic state.

The analysis revealed that the maternal serum concentrations of glucose, triglycerides, $\beta$-hydroxybutyrate, branched-chain amino acids, and creatinine were correlated with embryonic resorptions and malformations. These results are of interest with respect to the recent suggestion of an enhanced embryonic oxidative metabolism with subsequent generation of reactive oxygen species as a fundamental component of the teratogenic process in diabetic pregnancy (22-24).

\section{METHODS}

Animals. Rats from two outbred Sprague-Dawley-derived (sub)strains were used; $U$ rats were acquired from a local colony and $\mathrm{H}$ rats from a commercial breeder (ALAB, Sollentuna, Sweden). The offspring of diabetic $U$ rats exhibit an increased incidence of skeletal malformations, e.g. micrognathia and sacral dysgenesis $(10,11)$. Normal and manifestly diabetic (see below) female $\mathrm{U}$ and $\mathrm{H}$ rats were caged overnight with nondiabetic males of the same strain. Conception was verified by the presence of sperm in a vaginal smear the next morning, which was designated $\mathrm{d} 0$ of gestation. All rats were 3-4 mo old at the start of the experiment and housed pairwise in plastic cages with the exception of pregnant females who were kept in individual cages from d 0 of gestation and onward. All rats were subjected to $12 \mathrm{~h}$ alternating light and darkness and were fed a standard laboratory food (Ewos AB, Södertälje, Sweden) and tap water ad libitum. All experimental procedures as well as the treatment and housing of the animals were approved by the Animal Ethical Committee of the Medical Faculty of the University of Uppsala.

Induction of diabetes. Virgin female rats of each strain were given a single i.v. injection of streptozotocin (kindly donated by The Upjohn Co., Kalamazoo, MI) at a dose of $40 \mathrm{mg} / \mathrm{kg}$. The drug was dissolved in $0.01 \mathrm{M}$ citrate buffer $(\mathrm{pH} 4.5$ ) immediately before injection. One week later the nonfasting blood glucose concentration of each rat was measured using a Beckman Glucose Analyzer 2 (Beckman Instrument Inc., Fullerton, CA). Injected rats with glucose levels exceeding 20 $\mathrm{mmol} / \mathrm{L}$ were denoted manifestly diabetic and subsequently mated.

Gestation and metabolic assessment. The pregnant rats were weighed on the morning of $\mathrm{d} 0,6$, and 10 , after which a blood sample was taken from the tail for determination of serum metabolites (see below). During the $24 \mathrm{~h}$ immediately preceding cesarean section on the morning of $d 11$, the pregnant rats were individually kept in metabolic cages to allow the determination of their water and food intake, as well as their production of urine and feces.

Termination of gestation. On gestational d 11, between 0900 and $1200 \mathrm{~h}$, each pregnant rat was removed from the metabolic cage, weighed, and anesthetized with ether. A blood sample was drawn from the abdominal aorta, the rat was killed by cervical dislocation, and the whole uterus was dissected out and transferred to a Petri dish with saline. The conceptuses (each explant being composed of embryos plus yolk sac membrane) were separated from the surrounding decidual tissue and further dissected under a stereo microscope until the embryos were completely free of their membranes. Presence of heartbeat indicated a living embryo and the crown-rump length and number of somites were subsequently determined. Nonviable embryos, i.e. embryos without heartbeat and in various stages of resorption, were denoted "resorbed" and not analyzed further. The same decision was made for a few embryos $(<1 \%)$ with no heartbeat despite general morphology appro- 
priate for the developmental stage. Viable embryos with gross developmental defects (e.g. severe malrotation, abnormally open neural tube, or heart hypertrophy) were assigned a malformation score of 10 , embryos with mild defects (small tail twist or delayed closure of a single neural pore) were assigned a score of 1 and apparently normal embryos were given the score 0 .

The embryos were submerged into $0.5 \mathrm{~mL}$ of $0.5 \mathrm{M} \mathrm{NaOH}$, ultrasonically disrupted $(20 \mathrm{kHz}, 60 \mathrm{~W}$, Ultrasonic, MSE, London, UK) and left at $4^{\circ} \mathrm{C}$ overnight. Their DNA $(25,26)$ and protein (27) contents were subsequently measured.

Determination of serum metabolites. Maternal serum concentrations of D-glucose (28), fructosamine (29), triglycerides (30), cholesterol (31), creatinine (32), urea (33), glutamic oxaloacetic transaminase (EC 2.6.1.1), glutamic pyruvic transaminase (EC 2.6.1.2), and ALP (EC 3.1.3.1) $(34,35)$ were determined with the aid of a Cobas MIRA multichannel analyzer (Hoffman-La Roche, Basel, Switzerland). The metabolites were measured using standard reagent kits from Hoffman-La Roche (kit nos. 07-1097-0, 07-1121-7, 07-1444-5, 07-1099-7, 07-1421-6, and 07-1322-8, respectively) and the enzymes were measured using standard reagent kits from Boehringer Mannheim GmbH (Mannheim, Germany) (kit nos. 191337, 191345, and 415278, respectively).

For the determination of free amino acids, $50-\mu \mathrm{L}$ aliquots of the serum samples were deproteinized by the addition of 150- $\mu \mathrm{L}$ aliquots of buffered sulfosalicylic acid (36) containing norleucine as internal standard. Before analysis the tubes were centrifuged at $10000 \times g$ for $5 \mathrm{~min}$ and loaded into the sample chain of a Biotronik LC-5001 amino acid analyzer (EppendorfNetheler-Hinz Gmbh, Biotronik Division, Maintal, Germany). The chromatograms were integrated using a two-channel Shimadzu CR2-AX integrator (Shimadzu Co., Tokyo, Japan).

$\beta$-Hydroxybutyrate was determined by the aid of a Cobas MIRA multichannel analyzer using a standard kit (no. 310-UV, Sigma Chemical Co. Diagnostics, St. Louis, MO) (37). IGF-I was determined at Kabi Peptide Hormones (Stockholm, Sweden). The RIA was carried out on serum samples extracted by acid ethanol (38). Incubation was performed overnight at $4^{\circ} \mathrm{C}$, and the antigen-antibody complex was precipitated by the addition of a second antibody together with a small amount of polyethylene glycol. Samples were centrifuged, and radioactivity was counted in the pellet. The antibodies against IGF-I were kindly provided by Dr. P. Gluckman, Auckland, New Zealand. The standard used was recombinant human IGF-I.

Statistical evaluation. Differences between means were evaluated with the aid of ANOVA or with $\chi^{2}$ statistics (with Yates' correction), whichever method was applicable (39). Significant differences between and within groups were estimated by ANOVA, the applied test was Fischer's Protected Least Significant Difference (40), at the 95\% significance level. The statistical analyses were made with the program StatView (Abacus Concepts Inc., Berkeley, CA) for Macintosh.

The computational statistical system SAS (SAS Institute Inc., Cary, NC) was used in a GUTS version for a CPX 8/85 main frame computer (Uppsala University Data Center, Uppsala, Sweden). The SAS software procedures REG and STEPWISE were used to establish interdependence between the maternal and embryonic variables and to build multivariate linear regression models for the data.

The litter means of percent malformations, percent resorptions, number of implantations, crown-rump length, and somite numbers were regarded as response variables, and the organ weights and the metabolic data of the mothers were used as regressor variables. In particular, the data were pooled and dummy values were assigned to the rats for strain ( $\mathrm{H}$ rat given the value 0 , $U$ rats given the value 1). As maternal growth parameters, the weight on $\mathrm{d} 0$ and the increase during gestational $\mathrm{d} 0-10$ were used. Furthermore, the mean values of the concentrations on $\mathrm{d} 6$ and 10 of the metabolites displayed in Figures 3-6 were used, as well as the levels of $\beta$-hydroxybutyrate, IGF-I, and amino acids.

\section{RESULTS}

Maternal parameters. Diabetic pregnant rats showed less weight increase between gestational d 0 and 10 compared with normal pregnant rats, and UD rats had the lowest weight increase of all groups (Fig. 1). The UD animals had heavier livers than the UN animals, and both the UD and HD rats had heavier kidneys than their respective controls (Fig. 2). No differences were noted between the diabetic animals, but the HN rats had slightly heavier livers and kidneys than the UN rats. In general, diabetes caused increased concentrations of the measured serum metabolites, with a few differences within the normal and diabetic groups with regard to the strain of the rats (Figs. 3-7). The glucose concentrations of the diabetic rats were in excess of $30 \mathrm{mmol} / \mathrm{L}$ in both strains, a 5 -fold increase in comparison to the normal rats. On gestational d 6, the UD rats had slightly higher glucose concentration than the HD rats (Fig. 3), and when the data from both gestational days were combined, the difference between the UD $6+10(34 \pm 1$ $\mathrm{mmol} / \mathrm{L})$ and $\mathrm{HD} 6+10(31 \pm 2 \mathrm{mmol} / \mathrm{L})$ rats prevailed $(p<$ 0.05 , ANOVA). The fructosamine levels of the UD and HD rats were increased by $55 \%$ compared with the UN and $\mathrm{HN}$

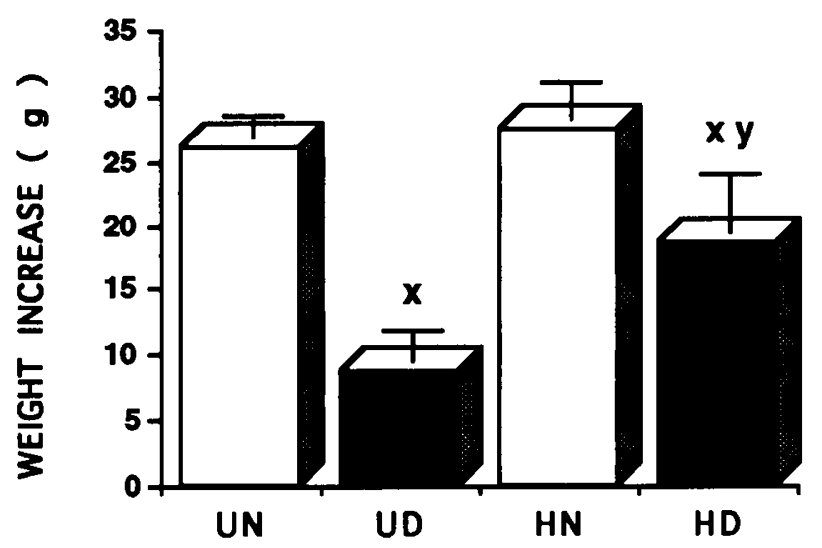

Figure 1. Increase in body weight (g) between gestational d 0 and 10 in normal (N) and manifestly diabetic (D) rats from the $\mathrm{U}$ and $\mathrm{H}$ strains. Values are given as means $+\operatorname{SEM}(9 \leq n \leq 14)$. Significance of the difference between means was determined by ANOVA. Significances: $x=p<0: 05 v s$ $\mathrm{N}$ embryos of same strain ( $\mathrm{U}$ or $\mathrm{H})$, i.e. comparisons $\mathrm{UD}$ vs $\mathrm{UN}$ and $\mathrm{HD}$ vs $\mathrm{HN}$; $y=p<0.05$ vs $\mathrm{U}$ embryos of same condition ( $\mathrm{N}$ or $\mathrm{D}$ ), i.e. comparisons $\mathrm{HN}$ $v s$ UN and HD vs UD. 

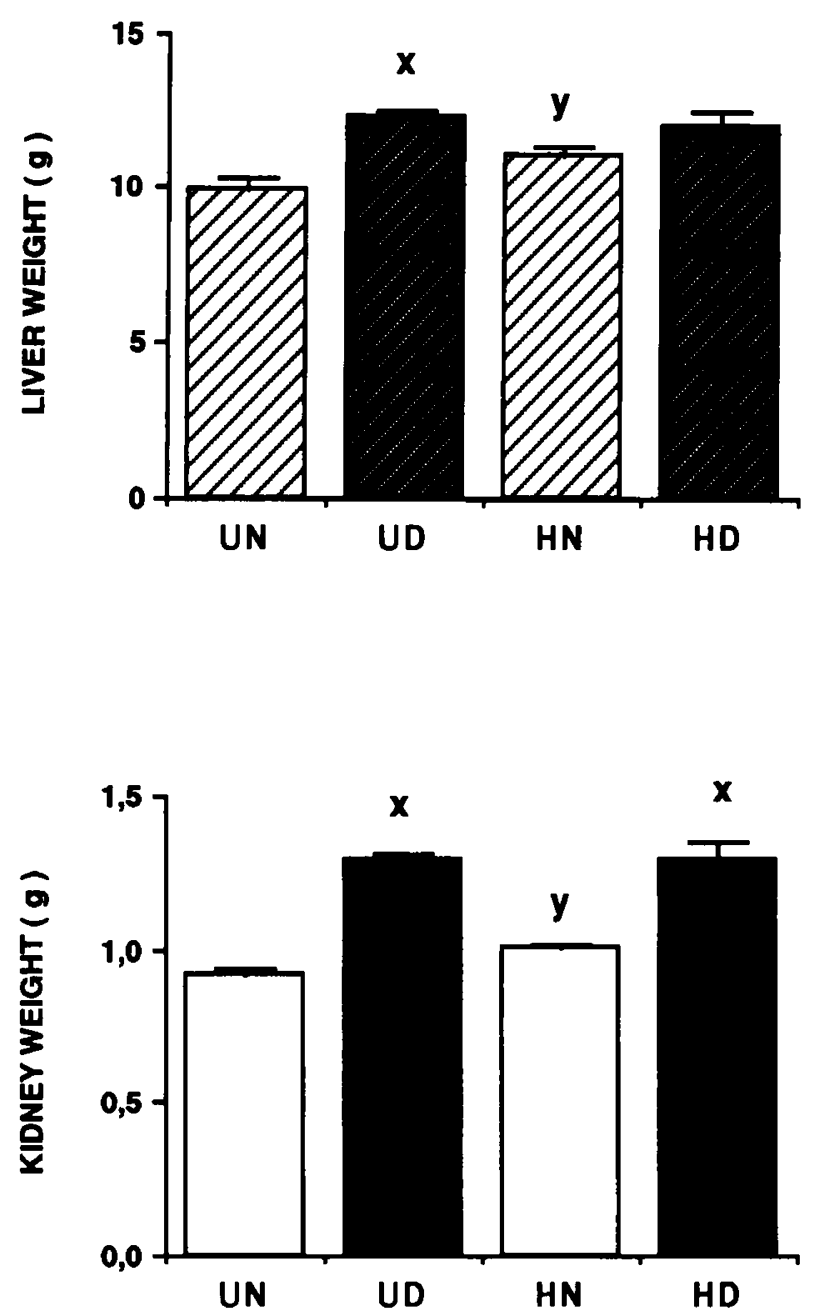

Figure 2. Weight of maternal liver (upper panel) and left kidney (lower panel) on gestational d 11 in normal $(\mathrm{N})$ and manifestly diabetic (D) rats from the $U$ and $H$ strains. Values are given as means $+\operatorname{SEM}(9 \leq n \leq 14)$. Significances by ANOVA: $x=p<0.05 v s \mathrm{~N}$ embryos of same strain (U or $\mathrm{H})$, i.e. comparisons UD $v s \mathrm{UN}$ and HD $v s$ HN; $y=p<0.05$ vs U embryos of same condition (N or D), i.e. comparisons $\mathrm{HN}$ vs $\mathrm{UN}$ and HD vs UD.

rats, respectively, both on $\mathrm{d} 6$ and 10 of gestation, with no difference between the strains (Fig. 3).

Increased serum levels of triglycerides were found in the UD rats on $\mathrm{d} 6$ and 10, whereas the HD rats showed a significant increase only at $\mathrm{d} 10$ (Fig. 4). Combining the data of the 2 gestational $\mathrm{d}$ within each strain yielded new groups (UD $6+$ 10: $4.0 \pm 0.7 \mathrm{mmol} / \mathrm{L}$, UN $6+10: 1.1 \pm 0.1 \mathrm{mmol} / \mathrm{L}$, HD 6 $+10: 2.8 \pm 0.6 \mathrm{mmol} / \mathrm{L}, \mathrm{HN} 6+10: 1.3 \pm 0.1 \mathrm{mmol} / \mathrm{L})$. The triglyceride concentrations of the diabetic rats were increased compared with the normal rats, that is when UD $6+10$ was compared with UN $6+10(p<0.001)$, and HD $6+10$ was compared with HN $6+10(p<0.05)$. This computation also disclosed a numerical difference between the UD $6+10$ and HD $6+10$ rats, which, however, failed to reach statistical significance. The cholesterol concentration of the diabetic rats did not differ from that of the nondiabetic rats, and there was no difference between the strain or with respect to the time of sampling (Fig. 4). Creatinine was increased in UD rats on $d 6$, and in both UD and HD rats on d 10 (Fig. 4). On gestational d 10 , the diabetic rats showed increased concentration of urea
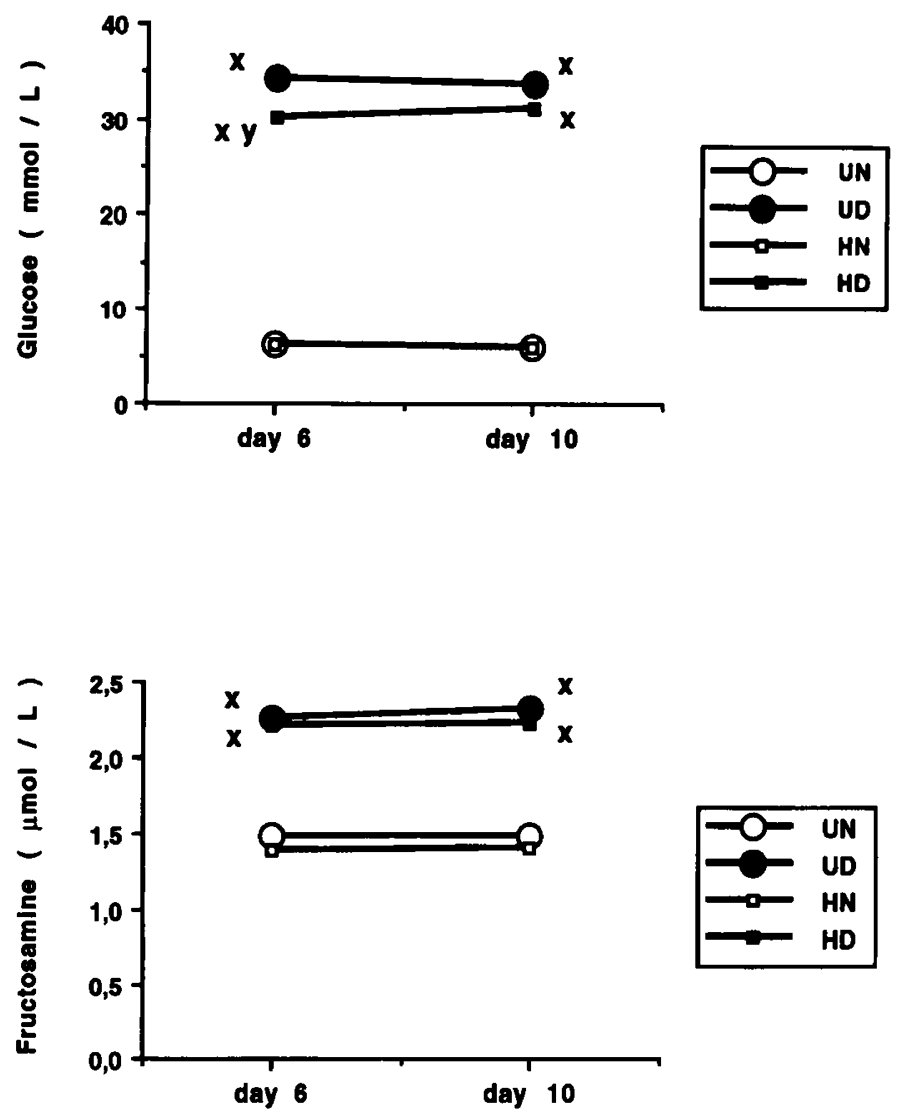

Figure 3. Maternal serum concentrations of glucose (upper panel) and fructosamine (lower panel) during gestational $\mathrm{d} 6-10$ in normal $(\mathrm{N})$ and manifestly diabetic (D) rats from the $U$ and $H$ strains, $9 \leq n \leq 14$. Significances by ANOVA: $x=p<0.05 v s \mathrm{~N}$ embryos of same strain ( $\mathrm{U}$ or $\mathrm{H}$ ), i.e. comparisons UD $v s$ UN and HD $v s \mathrm{HN} ; y=p<0.05 v s$ U embryos of same condition (N or D), i.e. comparisons HN vs UN and HD vs UD.

(Fig. 5), and increased activity of glutamic oxaloacetic transaminase, glutamic pyruvic transaminase, and ALP (Figs. 5 and 6). In addition, the UD rats had higher ALP activity than the HD rats (Fig. 6).

Diabetes altered the serum concentrations of several amino acids, most of which were increased (Fig. 7). Thus, we found elevated levels of asparagine (the concentrations in the UD and HD rats were 125 and $119 \%$ of the UN and HN levels, respectively), proline (137\% in both groups), alanine (114 and $135 \%$ in the $\mathrm{U}$ and $\mathrm{H}$ animals, respectively), citrulline (132 and $144 \%$ ), branced-chain amino acids (217 and $208 \%$, where valine, isoleucine, and leucine in both strains invariably showed more than doubled concentrations in the diabetic animals compared with the controls), tyrosine (120 and 109\%), and ornithine (209 and $118 \%$ ). In fact, the UD serum concentration of ornithine $(86 \pm 14 \mu \mathrm{mol} / \mathrm{L})$ was higher $(p<0.05$, ANOVA) than in all other groups (UN: $41 \pm 5 \mu \mathrm{mol} / \mathrm{L}, \mathrm{HD}$ : $51 \pm 8 \mu \mathrm{mol} / \mathrm{L}, \mathrm{HN}: 43 \pm 4 \mu \mathrm{mol} / \mathrm{L}$ ), and this amino acid showed the most pronounced strain difference in the response to diabetes. The serum concentrations of some amino acids were decreased by diabetes (Fig. 7), such as glutamic acid (69 and $64 \%$ ), glutamine ( 74 and $80 \%$ ), cystine ( $83 \%$ in both strains), and lysine (74 and $78 \%$ ). A third group of amino acids was virtually unaltered by diabetes; threonine (106 and 103\%), glycine (93 and 94\%), methionine (101 and 100\%), phenylal- 

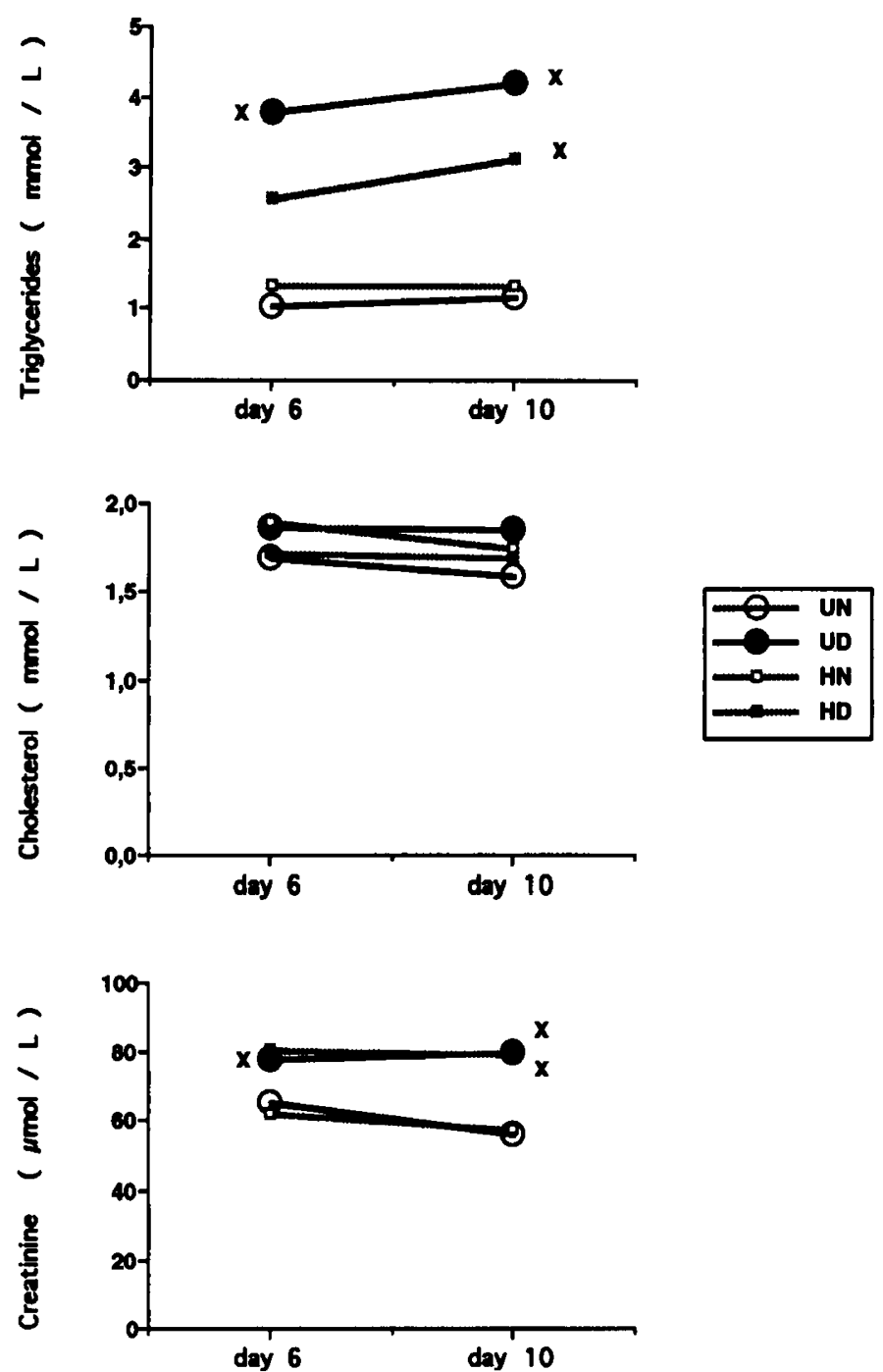

Figure 4. Maternal serum concentrations of triglycerides (upper panel), cholesterol (middle panel), and creatinine (lower panel) during gestational d 6-10 in normal $(\mathrm{N})$ and manifestly diabetic (D) rats from the $\mathrm{U}$ and $\mathrm{H}$ strains, $9 \leq$ $n \leq 14$. Significances by ANOVA: $x=p<0.05 v s \mathrm{~N}$ embryos of same strain ( $\mathrm{U}$ or $\mathrm{H})$, i.e. comparisons UD vs UN and HD vs HN.

anine ( $94 \%$ in both strains), and histidine (91 and 94\%). Three amino acids showed markedly asymmetrical response to diabetes with respect to strain. Thus, taurine ( 88 and $102 \%$ ), serine (96 and $84 \%$ ), and arginine (76 and $99 \%$ ) displayed differences in the $\mathrm{U}$ and $\mathrm{H}$ animals. The concentration changes in the two latter amino acids were ruled out by the ANOVA as nonsignificant, whereas the taurine alterations were of borderline significance. The taurine concentration of the UN rats (307 $\pm 27 \mu \mathrm{mol} / \mathrm{L})$ was higher $(p<0.05$, ANOVA) than the concentration in both the HN $(224 \pm 26 \mu \mathrm{mol} / \mathrm{L})$ and HD rats $(228 \pm 18 \mu \mathrm{mol} / \mathrm{L})$, whereas the suggested drop exerted by diabetes (UD: $269 \pm 24 \mu \mathrm{mol} / \mathrm{L}$ ) did not reach statistical significance.

The diabetic rats had higher intakes of food and water than the normal rats during the 24-h stay in the metabolic cage. The water intake was significantly decreased in the UN group compared with the HN rats, no other differences were noted between the groups (Fig. 8). The serum concentrations of $\beta$-hydroxybutyrate and IGF-I were increased in the diabetic
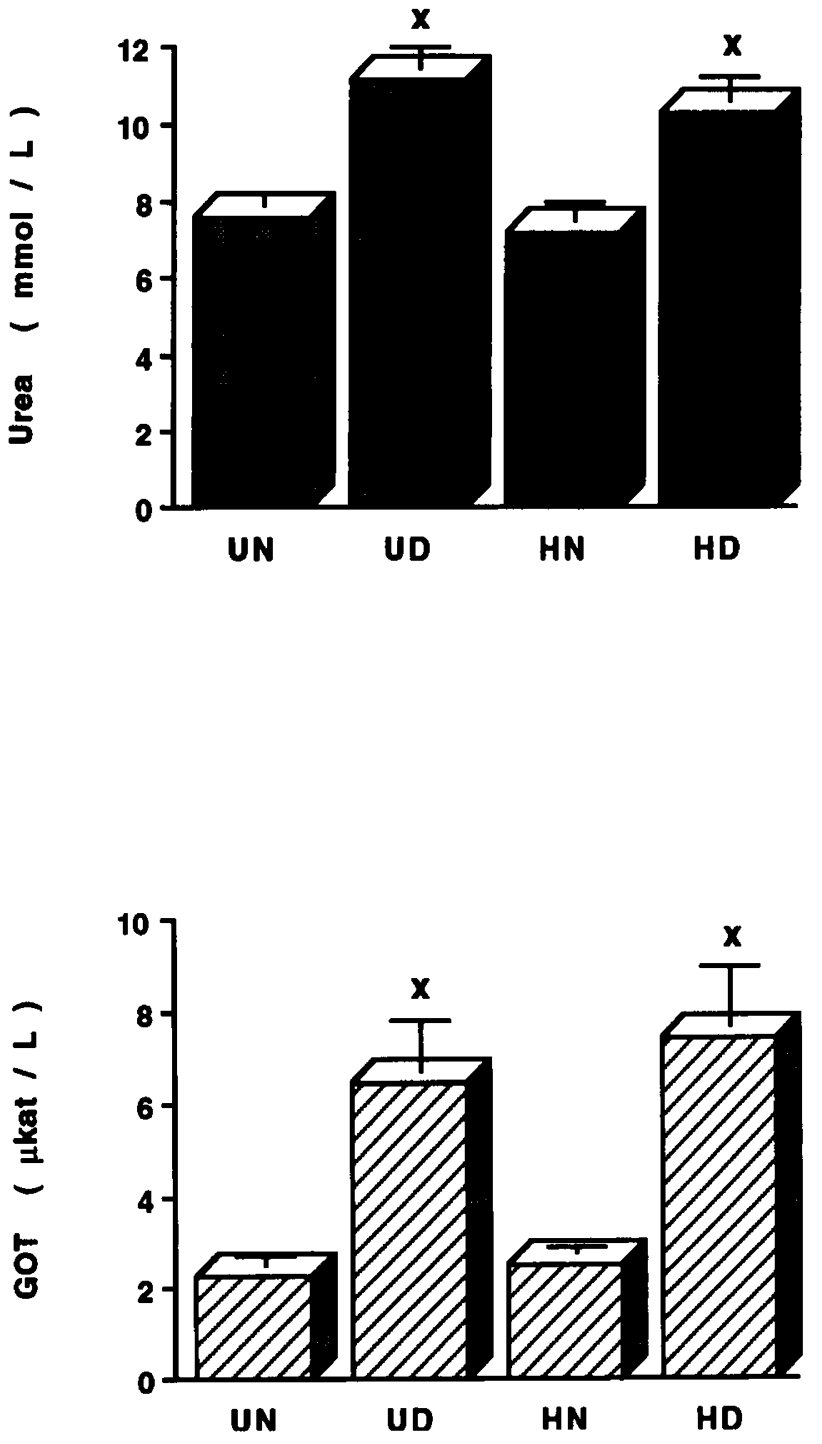

Figure 5. Mean maternal serum concentrations of urea (upper panel) and serum activity of glutamic oxaloacetic transaminase (GOT) (lower panel) during gestational d 6-10 in normal (N) and manifestly diabetic (D) rats from the $\mathrm{U}$ and $\mathrm{H}$ strains, $9 \leq n \leq 14$. Values are given as means + SEM. Significances by ANOVA: $x=p<0.05 v s \mathrm{~N}$ embryos of same strain (U or $\mathrm{H})$, i.e. comparisons UD $v s \mathrm{UN}$ and HD $v s \mathrm{HN}$.

rats, and the $\beta$-hydroxybutyrate concentration was slightly higher in the UD rats compared with the HD rats (Table 1).

Outcome of pregnancy. When the embryos were examined on $\mathrm{d} 11$ of pregnancy, there was no difference in number of implantations per litter in any of the groups (Table 2). The numbers of resorptions were increased in the diabetic animals, but the resorption percentages ( 13 versus $8 \%$ in the $U$ rats, 9 versus $4 \%$ in the $\mathrm{H}$ rats) failed to reach statistical significance. When the resorption rates were calculated for the pooled UN + HN and UD + HD offspring, the groups differed significantly (UN + HN: 19 resorbed of 296 implantations, UD + HD: 31 of 269 , which yields $p<0.05$ for $\mathrm{UN}+\mathrm{HN}$ versus UD + HD, $\chi^{2}$ statistics with Yates' correction). The diabetic $U$ rats showed an increased malformation rate (18 versus $4 \%, p<$ $0.05)$ and the $H$ rats displayed a similar trend (16 versus $2 \%$, $0.05<p<0.10$, Table 2). When the malformation rates were compared, the pooled groups differed markedly $(\mathrm{UN}+\mathrm{HN}$ : 

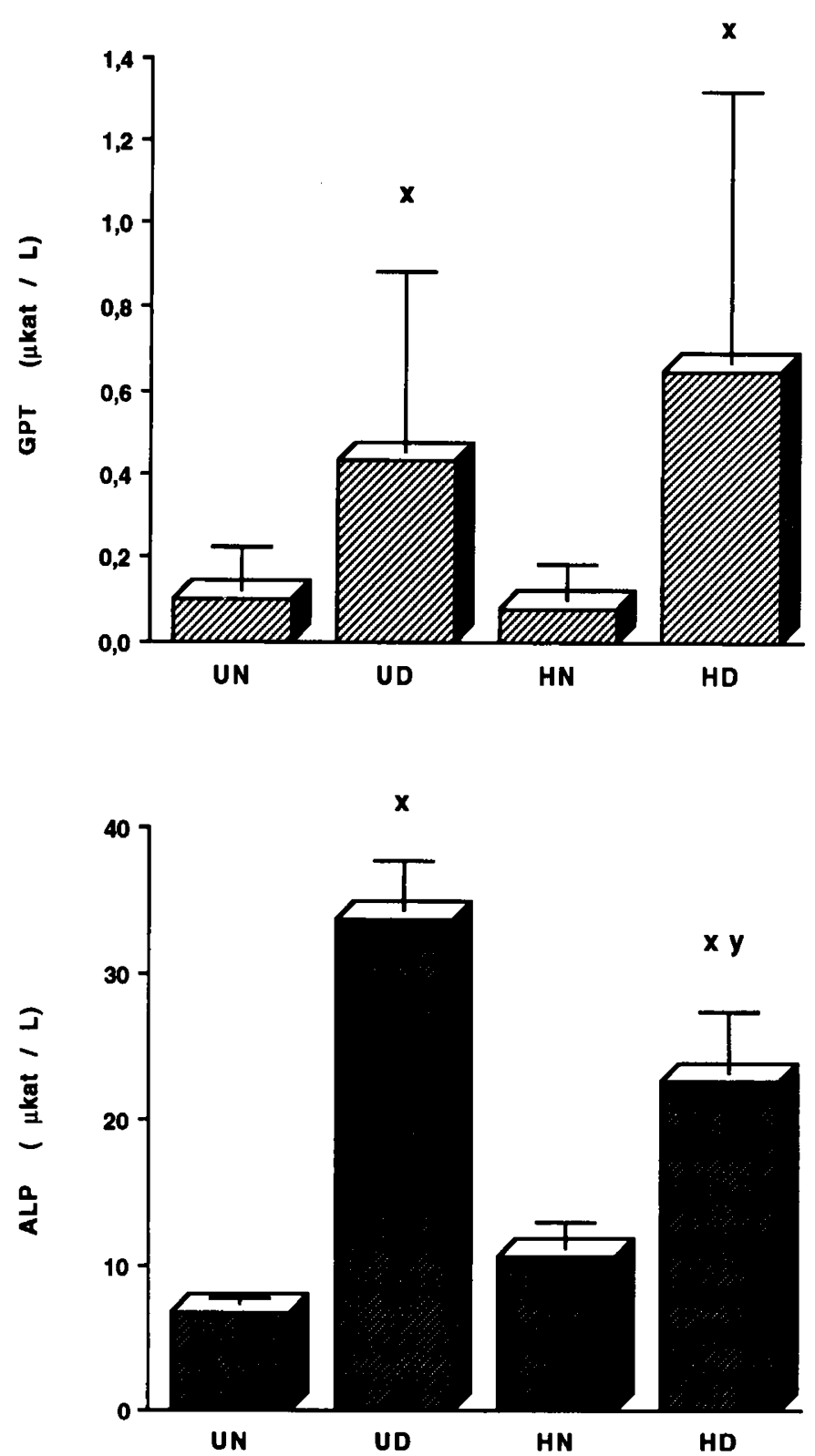

Figure 6. Mean maternal serum activity of glutamic pyruvic transaminase (GPT) (upper panel) and ALP (lower panel) during gestational d 6-10 in normal (N) and manifestly diabetic (D) rats from the $\mathrm{U}$ and $\mathrm{H}$ strains, $9 \leq n$ $\leq 14$. Values are given as means + SEM. Significances by ANOVA: $x=p<$ $0.05 v s \mathrm{~N}$ embryos of same strain ( $\mathrm{U}$ or $\mathrm{H}$ ), i.e. comparisons $\mathrm{UD} v s \mathrm{UN}$ and $\mathrm{HD}$ vs $\mathrm{HN} ; y=p<0.05$ vs $\mathrm{U}$ embryos of same condition $(\mathrm{N}$ or $\mathrm{D})$, i.e. comparisons $\mathrm{HN} v s \mathrm{UN}$ and HD vs UD.

nine malformed of 277 viable embryos, UD + HD: 39 of 238 , which yields $p<0.001$ for $\mathrm{UN}+\mathrm{HN}$ versus $\mathrm{UD}+\mathrm{HD}, \chi^{2}$ statistics). In addition, the malformational scores of the UD and HD embryos were increased in comparison with the corresponding scores of the UN and HN offspring (Fig. 9).

In the UN group the embryonic growth parameters (crownrump length, DNA, and protein contents) were lower than in the HN group (Table 3). Furthermore, in the UD group, these parameters were decreased compared with the HD rats (Table 3). Maternal diabetes reduced the crown-rump length by $23 \%$ in the $\mathrm{U}$ embryos (from 4.0 to $3.1 \mathrm{~mm}$ ) and by $16 \%$ in the $\mathrm{H}$ embryos (from 4.5 to $3.8 \mathrm{~mm}$ ), the reductions of DNA content (U: $46 \%, \mathrm{H}: 33 \%$ ), as well as protein content (U: $33 \%, \mathrm{H}$ :
$15 \%)$ showed the same pattern. In fact, the somite number, which did not differ significantly between the UN and $\mathrm{HN}$ rats, was decreased more by maternal diabetes in the $U$ strain than in the $\mathrm{H}$ strain (U: $8.7 \%$ decrease, $\mathrm{H}: 6.5 \%$ decrease), and was thus significantly lower ( $p<0.05$, ANOVA) in the UD rat offspring compared with the HD offspring (Table 3).

Statistical computation. The regressor variables were subjected to multiple linear regression analysis (SAS software procedure STEPWISE) during which it became evident that the organ weights, and the metabolic parameters (food and water intake, feces and urine production) could be expressed as linear combinations of the other regressor variables. These variables were therefore excluded from further statistical analysis. The three branched-chain amino acids (valine, leucine, and isoleucine) behaved almost identically in the correlation analysis, they were therefore combined for the multivariate computations. Furthermore, the neutral amino acids were combined into one regressor variable. In a second round of computations for a limited number of correlation analyses, the individual amino acids were entered as regressor variables instead of the combined values.

The final results of the multiple regression analysis, divided in two sets for the $\mathrm{N}$ and $\mathrm{D}$ rats, are shown in Tables 4 and 5. Individual regressors with $p$ values less than 0.10 were regarded as significantly correlated to the response variable.

For the normal animals, the variance varied between 0.12 (malformation percentage) and 0.70 (crown-rump length), indicating that the chosen regressor variables in the computed regression models were able to account for 12 to $70 \%$ of the variation of the response variables (Table 4). In particular, the malformation percentage was dependent on the $\beta$-hydroxybutyrate concentration, the resorption percentage on the IGF-I levels, the implantations showed a positive correlation with the maternal weight increase, whereas the crown-rump length was related to strain, and concentrations of urea, branched-chain amino acids, and fructosamine. The number of somites were influenced by the concentration of neutral amino acids and the activity of ALP (Table 4).

In the diabetic pregnant rat, the regression models were more successful in describing the data $(48-81 \%$ of the variation of the response variable accounted for) (Table 5). The malformation percentage was dependent on the strain and the concentration of $\beta$-hydroxybutyrate, creatinine, and glucose. The resorption percentage was explained to $68 \%$ by the maternal concentrations of triglycerides and branched-chain amino acids. The number of implantations was dependent on the maternal weight increase and the concentration of creatinine and urea. The crown-rump length was dependent on the maternal weight increase, the $\beta$-hydroxybutyrate concentration, and the ALP activity. The number of somites was determined by the maternal weight increase and the maternal levels of glucose and neutral amino acids (Table 5). In general, reanalyzing the data using the individual amino acids as regressor variables did not increase the explanatory value of the models (i.e. the variance) to any marked extent.

\section{DISCUSSION}

The study has demonstrated that maternal diabetes profoundly affects both growth and development of the offspring 

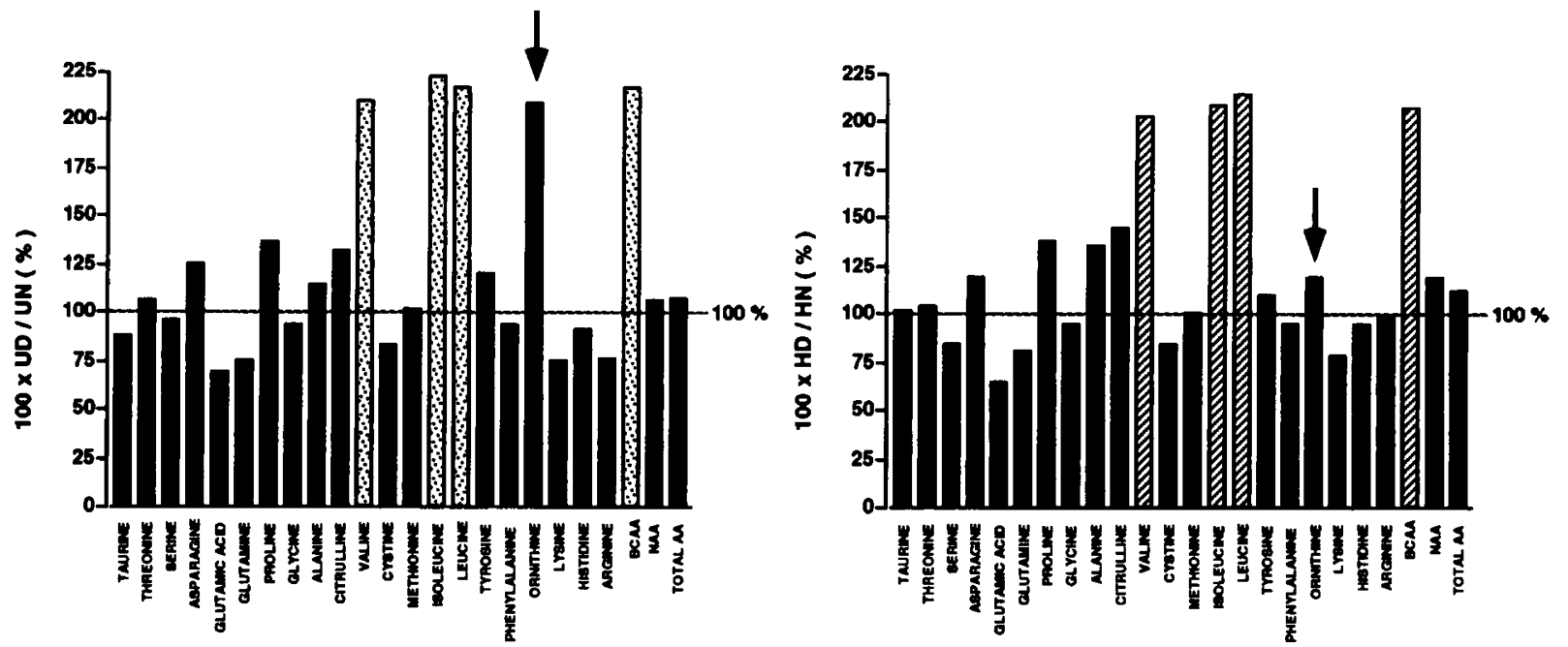

Figure 7. Maternal serum concentrations of amino acids in normal $(\mathrm{N})$ and manifestly diabetic (D) rats from the $\mathrm{U}$ (left) and $\mathrm{H}$ (right) strains on gestational d 11. The concentration of each amino acid in $\mathrm{D}$ rats is expressed in percent of the corresponding amino acid in $\mathrm{N}$ rats $(9 \leq n \leq 14)$. BCAA, branched-chain amino acids; NAA, neutral amino acids; and TOTAL AA, total amino acids. The arrows indicate the serum concentration of ornithine, the amino acid that showed the most pronounced difference between the two strains.

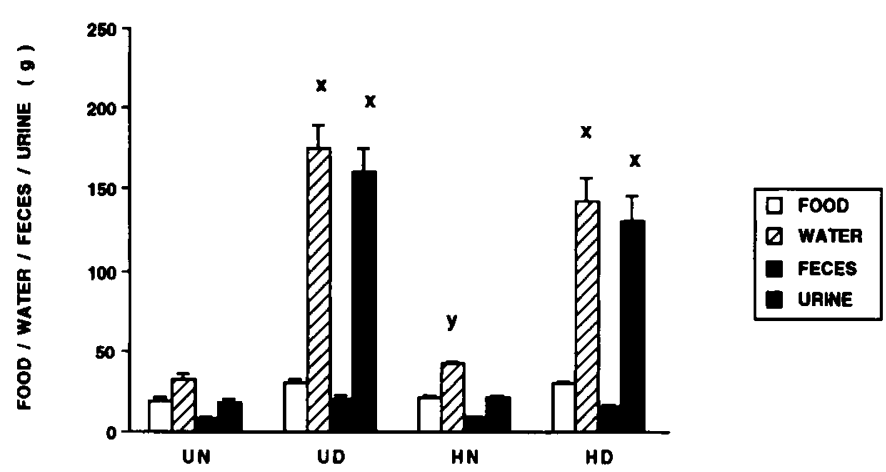

Figure 8. Intake of food and water and output of feces and urine in normal (N) and manifestly diabetic (D) rats from the $\mathrm{U}$ and $\mathrm{H}$ strains $(4 \leq n \leq 8)$. Values are given as means + SEM. Significances by ANOVA: $x=p<0.05$ vs $\mathrm{N}$ embryos of same strain ( $\mathrm{U}$ or $\mathrm{H}$ ), i.e. comparisons UD vs $\mathrm{UN}$ and HD vs $\mathrm{HN} ; y=p<0.05 v s \mathrm{U}$ embryos of same condition ( $\mathrm{N}$ or D), i.e. comparisons HN vs UN.

Table 1. Serum concentration of $\beta$-hydroxybutyrate and IGF-I in pregnant $N$ and $D$ rats from the $U$ and $H$ strains*

\begin{tabular}{cccc}
\hline & $n$ & $\begin{array}{c}\beta \text {-hydroxybutyrate } \\
(\mathrm{mmol} / \mathrm{L})\end{array}$ & \multicolumn{1}{c}{$\begin{array}{c}\text { IGF-I } \\
(\mu \mathrm{g} / \mathrm{L})\end{array}$} \\
\hline UN & 12 & $0.3 \pm 0.05$ & $831 \pm 40$ \\
UD & 14 & $1.1 \pm 0.1 \dagger$ & $513 \pm 50 \dagger$ \\
HN & 11 & $0.1 \pm 0.01$ & $898 \pm 50$ \\
HD & 9 & $0.8 \pm 0.1 \dagger \neq$ & $578 \pm 62 \dagger$ \\
\hline
\end{tabular}

* The compounds were measured on gestational $d 11$. Values are given as means \pm SEM. Significance of the difference between means was determined by one-way ANOVA.

$\dagger p<0.05 v s \mathrm{~N}$ embryos of same strain ( $\mathrm{U}$ or $\mathrm{H}$ ).

$\ddagger p<0.05$ vs $\mathrm{U}$ embryos of same condition ( $\mathrm{N}$ or $\mathrm{D}$ ).

as early as the embryonic stage. The previously reported differences between the outcome of pregnancy in diabetic $U$ and $\mathrm{H}$ rats, e.g. increased incidence of skeletal malformations and resorptions in the $U$ rat strain by the end of pregnancy (and low incidence of fetal dysmorphogenesis in diabetic $\mathrm{H}$ rat pregnancy) $(10,11)$, were not equally apparent among the d-11 embryos in our study. All the signs of maldevelopment of the
U offspring (malformational score, percent malformations, and percent resorptions), however, tended to be greater than those of the $\mathrm{H}$ embryos, thereby suggesting that the development of the $\mathrm{U}$ offspring is generally more affected by maternal diabetes than the development of the $\mathrm{H}$ offspring. The reason for the differences in apparent teratologic sensitivity when the offspring was assessed in early or late gestation, may be related to the difficulties in identifying the future (skeletal) malformations on $d 11$. Furthermore, the development of embryos between $\mathrm{d} 11$ and 20 entails a substantially greater proportion of resorptions in the $\mathrm{U}$ than in the $\mathrm{H}$ offspring, a fraction of future nonviable embryos that, again, were not identifiable on gestational $d 11$. Combining this finding with the previously demonstrated teratologic period in the $U$ rat between pregnancy $\mathrm{d} 6$ and $10(14)$, and the demonstration in our study of several UD maternal parameters being more altered by the diabetic state than corresponding HD parameters (i.e. maternal weight increase, the serum concentrations of glucose, $\beta$-hydroxybutyrate, triglyceride, and ornithine, as well as the serum ALP activity) suggests a specific interpretation of the dynamics of the $U$ rat model for diabetic pregnancy. It seems reasonable to assume that the $U$ rats are slightly more unbalanced metabolically during early pregnancy, and that this imbalance induces malformations and other disruptive processes. These embryonic changes are only barely detectable on gestational d 11 when this study was performed, but become much more evident during the subsequent intrauterine development with increased $U$ fetal morbidity and malformations $(11,12)$.

The fundamental difference between the $\mathrm{U}$ and $\mathrm{H}$ strains that predisposes to the higher teratologic $U$ vulnerability is not known, but could be related to different isoenzymes of catalase found in the strains (41). The malformation-prone $U$ rats have a different type of catalase than the nonmalformation-prone $\mathrm{H}$ rats. Whether this difference is of functional importance, i.e. yields a different capacity of the $U$ rats to metabolize free oxygen radicals, remains to be investigated. Alternatively, the polymorphism of the catalase gene may indicate that this area 
Table 2. Outcome of pregnancy in $N$ and $D$ rats of the $U$ and $H$ strains*

\begin{tabular}{ccccccccc}
\hline Group & $n$ & Implantations & Implantations/litter & Resorptions & Resorption (\%) & Viable & Malformations & Malformation (\%) \\
\hline UN & 12 & 154 & $12.8 \pm 1.2$ & 14 & $8 \pm 2$ & 140 & 6 & $4 \pm 1$ \\
UD & 14 & 155 & $11.1 \pm 0.5$ & 20 & $13 \pm 3$ & 135 & 22 & $18 \pm 6 \dagger$ \\
HN & 11 & 142 & $12.9 \pm 0.6$ & 5 & $4 \pm 2$ & 137 & 3 & 1 \\
HD & 9 & 114 & $12.7 \pm 0.8$ & 11 & $9 \pm 4$ & 103 & 17 & $16 \pm 7$ \\
\hline
\end{tabular}

* Outcome was assessed on $\mathrm{d} 11$ of pregnancy. $n$ denotes the number of pregnant animals in each group. Values are given as means \pm SEM. Significance of the difference between means was determined by ANOVA (implantations per litter) and $\chi^{2}$-statistics with Yates' correction (resorption and malformation percentages).

$\dagger p<0.05$ vs $\mathrm{N}$ embryos of same strain ( $\mathrm{U}$ or $\mathrm{H})$.

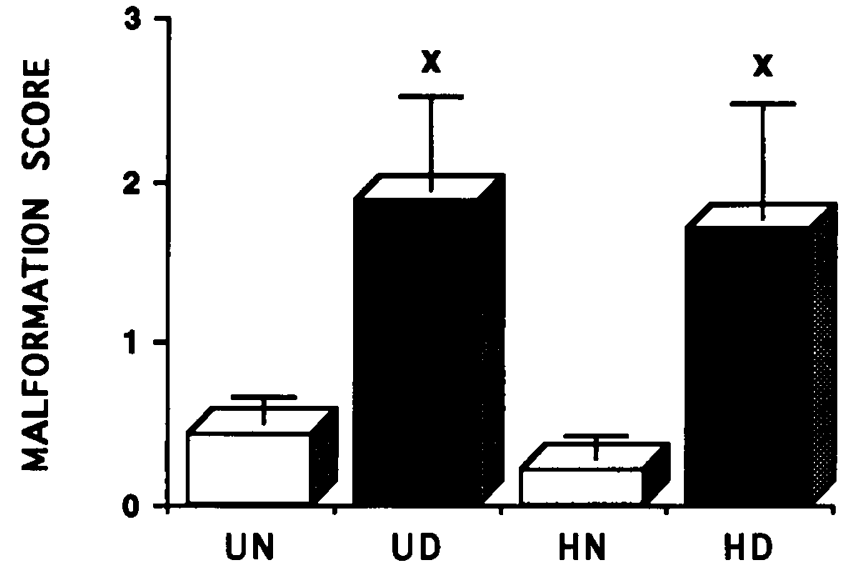

Figure 9. Mean malformational score in litters of embryos from normal $(N)$ and manifestly diabetic (D) rat mothers from the $U$ and $H$ strains on $d 11$. Values are given as means $+\operatorname{SEM}(9 \leq n \leq 14)$. Significances by ANOVA: $x=p<0.05$ vs $\mathrm{N}$ embryos of same strain ( $\mathrm{U}$ or $\mathrm{H}$ ), i.e. comparisons UD $v s$ $\mathrm{UN}$ and HD $v s \mathrm{HN}$.

of the U genome carries a higher than normal risk for DNA damage and gene polymorphism (41).

The statistical analysis of the data regarding diabetic rat pregnancy revealed significant interrelationships between adverse morphologic embryonic outcome (increased malformation and resorption percentages) and the maternal serum concentrations of glucose, triglycerides, $\beta$-hydroxybutyrate, the three branched-chain amino acids, and creatinine. This indicates that the maternal metabolism of the three major classes of nutrients covariates with the morphologic embryonic development. If this finding is relevant also for human diabetic pregnancy, then the monitoring of only one of these maternal factors, e.g. the serum glucose concentration, may not adequately predict the developmental status of the offspring.

Further experimental support for the view that other diabetes-associated substances than glucose may be teratogenic has been provided by the in vitro culture of embryos in high concentration of $\beta$-hydroxybutyrate (42-45), which yields em- bryonic malformations. Also, in micromass culture, excess $\beta$-hydroxybutyrate retards the growth of the (pre)chondrocytes from limb buds and mandibular arch tissue $(46,47)$. Recently, a derivative of a branched-chain amino acid has also been shown to be teratogenic in vitro. Thus, the transaminated product of leucine, $\alpha$-keto-isocaproic acid, is teratogenic in rat embryo culture at a concentration as low as $3 \mathrm{mmol} / \mathrm{L} \mathrm{(23).} \mathrm{In}$ a recent study, Buchanan et al. (48) reported that the teratogenic potential of serum from diabetic rats was dependent on other factors in addition to the elevated levels of glucose.

The experimental finding of the teratologic potential of diabetes-associated metabolites, in addition to glucose, agrees with the clinical observation that excellent control of the maternal serum glucose concentration is insufficient to protect the infants from congenital malformations (9). In addition, there are experimental observations in vitro where subteratogenic doses of several teratogenic substrates (glucose and $\beta$-hydroxybutyrate) constitute a teratogenic environment ( 23 , 49). Altogether these data would support the notion of a multiple origin of the embryonic maldevelopment in diabetic pregnancy $(23,48,50,51)$.

The association between maternal creatinine concentration and embryonic dysmorphogenesis is interesting in the context that the malformation-prone $U$ rats exhibit a higher degree of albuminuria than the $\mathrm{H}$ rats (52), and that impaired kidney function is often present in the diabetic women with the highest risk for adverse fetal outcome (53). We have previously demonstrated that normal pregnant $U$ rats on a zinc-deficient diet are more prone to have fetal skeletal malformations than $\mathrm{H}$ rats given the same diet (54). A leakage of albumin via the kidneys may predispose for trace metal shortage, because albumin serves as carrier and plasma reservoir for several of these, including zinc. Deficiency of zinc, and other trace metals, causes congenital malformations (55), and a coupling between increased urinary albumin excretion and fetal dysmorphogenesis via trace metal deficiency may constitute a teratogenic

Table 3. Development of $N$ and $D$ embryos of the $U$ and $H$ strains*

\begin{tabular}{crllllc}
\hline Group & $n$ & CR $(\mathrm{mm})$ & Somite no. & DNA $(\mu \mathrm{g})$ & Protein $(\mathrm{mg})$ & P/D ratio $\times 10^{3}$ \\
\hline UN & 12 & $4.0 \pm 0.1$ & $29.8 \pm 0.3$ & $23.3 \pm 1.0$ & $285 \pm 12$ & $12.9 \pm 0.5$ \\
UD & 14 & $3.1 \pm 0.1 \dagger$ & $27.2 \pm 0.5 \dagger$ & $12.6 \pm 0.9 \dagger$ & $192 \pm 12 \dagger$ & $15.7 \pm 0.5 \dagger$ \\
HN & 11 & $4.5 \pm 0.1 \ddagger$ & $30.8 \pm 0.2$ & $45.2 \pm 1.3 \ddagger$ & $441 \pm 17 \ddagger$ & $10.2 \pm 0.4 \ddagger$ \\
HD & 9 & $3.8 \pm 0.2 \dagger \ddagger$ & $28.8 \pm 0.6 \dagger \ddagger$ & $30.2 \pm 2.1 \dagger \ddagger$ & $375 \pm 18 \dagger \ddagger$ & $14.6 \pm 1.5$ \\
\hline
\end{tabular}

$\mathrm{P} / \mathrm{D}$, protein/DNA.

* Outcome was assessed on $\mathrm{d} 11$ of pregnancy. $n$ and CR denote the number of pregnant animals in each group and crown rump length, respectively. Values are given as means \pm SEM. Significance of the difference between means was determined by one-way ANOVA.

$\dagger p<0.05$ vs $\mathrm{N}$ embryos of same strain $(\mathrm{U}$ or $\mathrm{H})$.

$\ddagger p<0.05$ vs $\mathrm{U}$ embryos of same condition ( $\mathrm{N}$ or $\mathrm{D}$ ). 
Table 4. Multivariate regression analysis of embryonic outcome in normal rat pregnancy

\begin{tabular}{|c|c|c|c|c|}
\hline Response variable & $R^{2}$ & Regressor variable & $\begin{array}{c}\text { Regressor } \\
\text { constant }\end{array}$ & $p$ \\
\hline Malformation (\%) (per litter) & 0.12 & $\beta$-Hydroxybutyrate & 11.0 & 0.11 \\
\hline Resorption (\%) (per litter) & 0.32 & IGF-I & -0.02 & 0.01 \\
\hline No. of implantations (per litter) & 0.25 & Maternal wt increase & 0.2 & 0.01 \\
\hline \multirow[t]{4}{*}{ Crown rump length (per embryo) } & 0.70 & Strain & -0.7 & 0.0001 \\
\hline & & Urea & 0.2 & 0.001 \\
\hline & & BCAA & -0.003 & 0.01 \\
\hline & & Fructosamine & 0.7 & 0.07 \\
\hline \multirow[t]{2}{*}{ No. of somites (per embryo) } & 0.42 & Neutral amino acids & -0.005 & 0.02 \\
\hline & & ALP & 0.1 & 0.03 \\
\hline
\end{tabular}

The regressor variables with $p<0.1$ are regarded as significantly correlated with the response variable (SAS STEPWISE procedure). $R^{2}$, variance; BCAA, branched-chain amino acids.

Table 5. Multivariate regression analysis of embryonic outcome in diabetic rat pregnancy

\begin{tabular}{|c|c|c|c|c|}
\hline Response variable & $R^{2}$ & Regressor variable & $\begin{array}{c}\text { Regressor } \\
\text { constant }\end{array}$ & $p$ \\
\hline \multirow[t]{4}{*}{ Malformation (\%) (per litter) } & 0.76 & $\beta$-Hydroxybutyrate & 38.0 & 0.0001 \\
\hline & & Creatinine & -0.8 & 0.0001 \\
\hline & & Strain & -17.5 & 0.01 \\
\hline & & Glucose & 1.7 & 0.01 \\
\hline \multirow[t]{2}{*}{ Resorption (\%) (per litter) } & 0.68 & Triglycerides & 2.6 & 0.01 \\
\hline & & BCAA & 0.01 & 0.03 \\
\hline \multirow[t]{3}{*}{ No. of implantations (per litter) } & 0.48 & Maternal wt increase & 0.1 & 0.001 \\
\hline & & Creatinine & -0.1 & 0.008 \\
\hline & & Urea & 0.6 & 0.05 \\
\hline \multirow[t]{3}{*}{ Crown rump length (per embryo) } & 0.82 & Maternal wt increase & 0.02 & 0.003 \\
\hline & & $\beta$-Hydroxybutyrate & -0.5 & 0.01 \\
\hline & & ALP & -0.01 & 0.04 \\
\hline \multirow[t]{3}{*}{ No. of somites (per embryo) } & 0.51 & Maternal wt increase & 0.1 & 0.01 \\
\hline & & Glucose & -0.2 & 0.03 \\
\hline & & Neutral amino acids & -0.01 & 0.08 \\
\hline
\end{tabular}

The regressor variables with $p<0.1$ are regarded as significantly correlated with the response variable (SAS STEPWISE procedure). $R^{2}$, variance; BCAA, branched-chain amino acids.

mechanism of diabetic pregnancy in animals $(56,57)$, and man $(58,59)$.

The most important of the maternal parameters correlating with embryonic implantation rate, crown-rump length, and number of somites was the maternal weight increase during pregnancy. This parameter should reflect maternal metabolic perseverance despite the diabetic state. In addition, the maternal concentrations of creatinine, urea, $\beta$-hydroxybutyrate, glucose, and neutral amino acids, as well as the ALP activity, were associated with numbers of implantations, crown-rump length, and somite number in diabetic rat pregnancy. These factors overlapped to some extent, but not completely, with the set of maternal parameters associated with adverse embryonic outcome, thus suggesting similar, but not identical, modes of affecting the normal and abnormal development of the embryos.

In this context, the findings of altered psychomotor development at the ages of 2 and 6-9 y in children of diabetic mothers are interesting, especially because an association between maternal antepartum concentrations of $\beta$-hydroxybutyrate and postpartum intellectual development of the children was reported (60).

Mathematical correlation between regression variables does not imply, however, that a causative relationship exists be- tween them. The degree of "explanation" offered by the statistical analysis is purely mathematical in nature and, therefore, open to interpretational attempts. The relatively high explanatory values of the regression models for embryonic outcome in diabetic pregnancy suggest that the major serum factors with predictive value in this animal model have been identified in the present analysis. By contrast, several of the maternal factors that covariate, and possibly influence, the outcome of nondiabetic pregnancy were apparently not found in our study. With exception of the analysis of the crown-rump length, the best fitting regression models for the fetal parameters in normal pregnancy could only account for 12 and $42 \%$ of the variations, a result implicating the need for further search for explanatory maternal variables in nondiabetic gestation.

The majority of the maternal serum compounds associated with adverse fetal outcome are readily metabolizable by the embryo, such as glucose, triglycerides (preferably as fatty acids and glycerol), $\beta$-hydroxybutyrate, and the three branchedchain amino acids. This fact supports the notion that nutrients may act as teratogens by enhancing the embryonic oxidative metabolism. One possible effect of an augmented embryonic oxidation of substrates would be increased production of free oxygen radicals, preferably by the embryonic mitochondria. This view has obtained recent experimental support, because 
increased activity of oxygen radical metabolizing enzymes has been shown to diminish the teratogenic effect of increased concentrations of glucose, $\beta$-hydroxybutyrate, or $\alpha$-ketoisocaproic acid (the transaminated $\alpha$-ketoacid of leucine) in vitro (22-24). Furthermore, substantially altered mitochondrial morphology, a high-amplitude swelling, has recently been demonstrated in early embryos subjected to a diabetic environment, both in vivo and in vitro (61). These findings support a role for oxygen radicals in conjunction with a changed mitochondrial function in the teratogenic process of diabetic pregnancy.

The combined results of the present and previous studies suggest that the pathogenesis of fetal malformations in diabetic pregnancy is associated with altered serum concentration of several maternal nutrients. The teratogenic process appears to be multifactorial in nature, and the maintenance of maternal serum metabolites from all major nutrient classes at a normal level should be of fundamental importance for the prevention of adverse fetal outcome in diabetic pregnancy.

Acknowledgments. The authors thank Professor Claes Hellerström for fruitful discussions during the course of these investigations and Parri Wentzel for excellent technical assistance. They are also indebted to Gina L. Eriksson for her competent handling of the large volume of initial statistical data, and Dr. Allan Kofoed-Enevoldsen, Steno Memorial Hospital, Copenhagen, Denmark, for supplying crucial information regarding the analysis of serum $\beta$-hydroxybutyrate. Drs. Anna Skottner and Linda Fryklund, Kabi Peptide Hormones, Stockholm, Sweden, are gratefully acknowledged for the analyses of serum IGF-I.

\section{REFERENCES}

1. Kucera J 1971 Rate and type of congenital anomalies among offspring of diabetic women. J Reprod Med 7:61-70

2. Freinkel N 1980 Banting lecture. Of pregnancy and progeny. Diabetes 29:10231035

3. Mills J 1982 Malformations in infants of diabetic mothers. Teratology 25:385-394

4. Miller E, Hare JW, Cloherty JP, Dunn PJ, Gleason RE, Soeldner JS, Kitzmiller JL 1981 Elevated maternal hemoglobin A1C in early pregnancy and major congenital anomalies in infants of diabetic mothers. N Engl J Med 304:1331-1334

5. Baker L, Egler JM, Klein SH, Goldman AS 1981 Meticulous control of diabetes during organogenesis prevents congenital lumbosacral defects in rats. Diabetes 30:955-959

6. Eriksson UJ, Dahlström E, Larsson KS, Hellerström C 1982 Increased incidence of congenital malformations in the offspring of diabetic rats and their prevention by maternal insulin therapy. Diabetes 31:1-6

7. Ylinen K, Aula P, Stenman U-H, Kesäniemi-Konkkanen T, Teramo K 1984 Risk of minor and major fetal malformations in diabetics with high haemoglobin Alc values in early pregnancy. BMJ 289:345-346

8. Fuhrmann K, Reiher H, Semmler K, Glöckner E 1984 The effect of intensified conventional insulin therapy before and during pregnancy on the malformation rate in offspring of diabetic mothers. Exp Clin Endocrinol 83:173-177

9. Mills JL, Knopp RH, Simpson JL, Jovanovic-Peterson L, Metzger BE, Holmes LB, Aarons JH, Brown Z, Reed GF, Bieber FR, Van Allen M, Holzman I, Ober C, Peterson CM, Withiam MJ, Duckles A, Mueller-Heubach E, Polk BF, National Institute of Child Health and Human Development Diabetes in Early Pregnancy Study 1988 Lack of relation of increased malformation rates in infants of diabetic mothers to glycemic control during organogenesis. N Engl J Med 318:671-676

10. Eriksson UJ, Dahlström VE, Styrud J 1985 Metabolically-determined teratogenesis: malformations and maternal diabetes. Trans Biochem Soc 13:79-82

11. Eriksson UJ 1988 Importance of genetic predisposition and maternal environment for the occurrence of congenital malformations in the offspring of diabetic rats. Teratology 37:365-374

12. Eriksson UJ, Dahlström VE, Lithell HO 1986 Diabetes in pregnancy: influence of genetic background and maternal diabetic state on the incidence of skeletal malformations in the fetal rat. Acta Endocrinol (Copenh) 112(suppl 277):66-73

13. Mills J, Baker L, Goldman AS 1979 Malformations in infants of diabetic mothers occur before the seventh gestational week. Diabetes 28:292-293

14. Eriksson RSM, Thunberg L, Eriksson UJ 1989 Effects of interrupted insulin treatment on fetal outcome of pregnant diabetic rats. Diabetes 38:764-772
15. Eriksson UJ, Bone AJ, Turnbull DM, Baird JD 1989 Timed interruption of insulin therapy in diabetic BB/E rat pregnancy: effects on maternal metabolism and fetal outcome. Acta Endocrinol (Copenh) 120:800-810

16. Kim JN, Runge W, Wells LJ, Lazarow A 1960 Effects of experimental diabetes on the offspring of the rat. Fetal growth, birth, weight, gestation period and fetal mortality. Diabetes 9:396-404

17. Sybulski S, Maughan GB 1971 Use of streptozotocin as a diabetic agent in pregnant rats. Endocrinology 89:1537-1540

18. Brownscheidle CM, Wootten V, Mathieu MH, Davis DL, Hofman IA 1983 The effects of maternal diabetes on fetal maturation and neonatal health. Metabolism 32(suppl 1):148-155

19. Giavini E, Brocca ML, Prati M, Roversi GD, Vismara C 1986 Effects of streptozotocin-induced diabetes on fetal development of the rat. Teratology 34:81-88

20. Eriksson UJ, Lewis NJ, Freinkel N 1984 Growth retardation during early organogenesis in embryos of experimentally diabetic rats. Diabetes 33:281-284

21. Bhaumick B, Danilkewich AD, Bala RM 1986 Insulin-like growth factors (IGF) I and II in diabetic pregnancy: suppression of normal pregnancy-induced rise of IGF-I. Diabetologia 29:792-797

22. Eriksson UJ, Borg LAH 1991 Protection by free oxygen radical scavenging enzymes against glucose-induced embryonic malformations in vitro. Diabetologia 34:325-331

23. Eriksson UJ, Borg LAH 1993 Diabetes and embryonic malformations: role of substrate-induced free-oxygen radical production for dysmorphogenesis in cultured rat embryos. Diabetes 42:411-419

24. Eriksson UJ, Borg LAH, Hagay Z, Groner Y 1993 Increased superoxide dismutase (SOD) activity in embryos of transgenic mice protects from the teratogenic effects of a diabetic environment. Diabetes 42(suppl 1):85A(abstr)

25. Kissane JM, Robins E 1958 The fluorometric measurement of deoxyribonucleic acid in animal tissues with special reference to the central nervous system. J Biol Chem 223:184-188

26. Hinegardner RT 1971 An improved fluorometric assay for DNA. Anal Biochem 39:197-201

27. Lowry OH, Rosenbrough NJ, Farr AL, Randall RJ 1951 Protein measurement with the folin phenol reagent. J Biol Chem 193:265-275

28. Bondar RJL, Mead DC 1974 Evaluation of glucose-6-phosphate dehydrogenase from Leuconostoc mesenteroides in the hexokinase method for determining glucose in serum. Clin Chem 20:586-590

29. Baker JR, Metcalf PA, Johnson RN, Newman D, Rietz P 1985 Use of protein-based standards in automated colorimetric determination of fructosamine in serum. Clin Chem 31:1550-1554

30. Megraw EM, Dunn DE, Biggs HG 1979 Manual and continuous-flow colorimetry of triacylglycerois by a fully enzymatic method. Clin Chem 25:273-278

31. Allain CC, Poon LS, Chon CSG, Richmond U, Fu PC 1974 Enzymatic determination of total serum cholesterol. Clin Chem 20:470-475

32. Fabiny DL, Ertinghausen G 1971 Automated reaction-rate method for determination of serum creatinine with the CentrifiChem. Clin Chem 17:696-700

33. Eisenweiner HG 1976 Kinetische Bestimmung des Harnstoffes mit dem LKB-System. J Clin Chem Clin Biochem 14:261-264

34. Strömme J, Eldjarn L 1974 Editorial: Scandinavian standardisations of enzyme determination. Scand J Clin Lab Invest 33:287-289

35. Hafkenscheid JC, Kohler BE 1986 Temperature-conversion factors for four enzymes in commercial control sera. Clin Chem 32:1616

36. Mondino A, Bongiovanni G, Fumero S, Rossi L 1972 An improved method of plasma deproteination with sulphosalicylic acid for determining amino acids and related compounds. J Chromatogr 74:255-263

37. Custer EM, Myers JL, Poffenbarger PL, Schoen I 1983 The storage stability of 3-hydroxybutyrate in serum, plasma and whole blood. Am J Clin Pathol 80:375380

38. Daughaday W, Mariz I, Blethen S 1980 Inhibition of access of bound somatomedin to membrane receptors and immunobinding sites: a comparison of radio receptor and radio immunoassay of somatomedin in native and acid ethanol extracted serum. J Clin Endocrinol Metab 51:781-788

39. Ostle B 1963 Statistics in Research, 2nd Ed. Iowa State University Press, Ames, IA

40. Winer BJ 1971 Statistical Principles in Experimental Design. McGraw-Hill, New York

41. Eriksson UJ, den Bieman M, Prins JB, van Zutphen LFM 1990 Differences in susceptibility for diabetes induced malformations in separated rat colonies of common origin. Proceedings of the 4th FELASA Symposium, Lyon, France, pp 53-57

42. Horton WE, Sadler TW 1983 Effects of maternal diabetes on early embryogenesis. Alterations in morphogenesis produced by the ketone body, $\beta$-hydroxybutyrate. Diabetes 32:610-616

43. Sheehan EA, Beck F, Clarke CA, Stanisstreet M 1985 Effects of $\beta$-hydroxybutyrate on rat embryos grown in culture. Experientia 41:273-275

44. Hunter ES, Sadler TW, Wynn RE 1987 A potential mechanism of DL- $\beta$ hydroxybutyrate-induced malformations in mouse embryos. Am J Physiol 253:E72E80

45. Moore DCP, Stanisstreet M, Clarke CA 1989 Morphological and physiological effects of $\beta$-hydroxybutyrate on rat embryos grown in vitro at different stages. Teratology 40:237-251

46. Styrud J, Eriksson UJ 1990 Effects of D-glucose and $\beta$-hydroxybutyric acid on the in vitro development of (pre)chondrocytes from embryos of normal and diabetic rats. Acta Endocrinol (Copenh) 122:487-498

47. Styrud J, Unger E, Eriksson UJ 1990 Metabolism in vitro of cartilage proteoglycans in rat (pre)chondrocytes from different embryonic regions. Upsala J Med Sci 95:31-44 
48. Buchanan TA, Denno KM, Sipos GF, Sadler TW 1994 Diabetic teratogenesis: In vitro evidence for a multifactorial etiology with little contribution from glucose per se. Diabetes 43:656-660

49. Lewis NJ, Akazawa S, Freinkel N 1983 Teratogenesis from beta-hydroxybutyrate during organogenesis in rat embryo organ culture and enhancement by subteratogenic glucose. Diabetes 32(suppl 1):11A(abstr)

50. Freinkel N, Cockroft DL, Lewis NJ, Gorman L, Akazawa S, Phillips LS, Shambaugh III GE 1986 Fuel-mediated teratogenesis during early organogenesis: the effects of increased concentrations of glucose, ketones, or somatomedin inhibitor during rat embryo culture. Am J Clin Nutr 44:986-995

51. Sadler TW, Hunter III ES, Wynn RE, Phillips LS 1989 Evidence for multifactorial origin of diabetes-induced embryopathies. Diabetes 38:70-74

52. Kofoed-Enevoldsen A 1992 Inhibition of glomerular glucosaminyl N-deacetylase in diabetic rats. Kidney Int 41:763-767

53. Pedersen J 1977 The Pregnant Diabetic and Her Newborn. Problems and Management, 2nd Ed. Munksgaard, Copenhagen

54. Styrud J, Dahlström VE, Eriksson UJ 1986 Induction of skeletal malformations in the offspring of rats fed a zinc-deficient diet. Upsala J Med Sci 91:29-36
55. Hurley LS 1981 Teratogenic aspects of manganese, zinc, and copper nutrition. Physiol Rev 61:249-295

56. Eriksson UJ 1984 Diabetes in pregnancy: Retarded fetal growth, congenital malformations and feto-maternal concentrations of zinc, copper and manganese in the rat. $J$ Nutr 114:477-486

57. Uriu-Hare JY, Stern JS, Reaven GM, Keen CL 1985 The effect of maternal diabetes on trace element status and fetal development in the rat. Diabetes 34:1031-1040

58. Jameson S 1976 Effects of zinc deficiency in human reproduction. Acta Med Scand (suppl 593):1-89

59. Breskin MW, Worthington-Roberts BS, Knopp RH, Brown Z, Plovie B, Mottet NK, Mills JL 1983 First trimester serum zinc concentrations in human pregnancy. Am J Clin Nutr 38:943-953

60. Rizzo T, Metzger B, Cho N 1994 Fuel-mediated behavioural teratogenesis: Correlations between antepartum maternal metabolism and child psychomotor development at ages 2 and 6-9 years. Diabetes 43(suppl 1):135A(abstr)

61. Yang X, Borg LAH, Eriksson UJ 1995 Altered mitochondrial morphology in embryos subjected to a diabetic environment. Anat Rec 241:255-267

\section{Erratum}

In the December 1994 issue, an author of a reference was omitted in the article "Exposure to Alternating Hypoxia and Hyperoxia Causes Severe Proliferative Retinopathy in the Newborn Rat" by Penn et al. on pages 724-731. Reference 10 should have read as follows: 10. D'Amato RD, Wesolowski E, Smith L 1993 Microscopic visualization of the retina by angiopathy with high-molecular-weight fluorescein-labeled dextrans in the mouse. Microvasc Res 46:135-142. The authors regret the omission. 